\title{
ON THE OSCILLATION OF SECOND ORDER LINEAR IMPULSIVE DIFFERENTIAL EQUATIONS
}

\section{Chenguun Guo And Zhiting Xu}

Abstract. For the second order linear impulsive differential equation with oscillatory coefficient

$$
\left\{\begin{array}{l}
\left(r(t) x^{\prime}(t)\right)^{\prime}+h(t) x(t)=0, \quad t \neq t_{k}, t_{k} \geqslant t_{0}, k=1,2, \cdots, \\
x\left(t_{k}^{+}\right)=a_{k} x\left(t_{k}\right), x^{\prime}\left(t_{k}^{+}\right)=b_{k} x^{\prime}\left(t_{k}\right), \quad k=1,2, \cdots, \\
x\left(t_{0}^{+}\right)=x_{0}, x^{\prime}\left(t_{0}^{+}\right)=x_{0}^{\prime},
\end{array}\right.
$$

where $h$ can be changed sign on $\left[t_{0}, \infty\right)$, by using the equivalence transformation, we establish an associated impulsive differential equation with damping and give oscillation criteria for the equation. As applications, we obtain oscillation theorems for Eq.(E). Moveover, an example is also given to illustrate the relevance of the results.

Mathematics subject classification (2010): 34A37, 34C10.

Keywords and phrases: oscillation, impulsive, linear differential equations, oscillatory coefficient.

\section{REFERENCES}

[1] R. P. Agarwal, S. R. Grace, D. O'Regan, Oscillation Theory for Second Order Dynamic Equations, Taylar \& Francis, London and New York, 2003.

[2] Y. S. ChEn, W. Z. Feng, Oscillations of second order nonlinear ODE with impulses, J. Math. Anal. Appl., 210 (1997), 150-169.

[3] L. P. Gimenes, M. Federson, Oscillation by impulses for a second order delay differential equations, Comput. Math. Appl., 52, 6-7 (2006), 819-828.

[4] Z. M. HE, W. G. GE, Oscillations of second-order nonlinear impulsive ordinary differential equations, J. Comput. Appl. Math., 158 (2003), 397-406.

[5] V. Lakshimikantham, D. D. Bainov, P. S. Simeonov, Theory of Impulsive Differential Equations, World Scientific Publishers, Singapore, New Jersey, London, 1989.

[6] J. W. Luo, Second order quasilinear oscillation with impulsive, Comput. Math. Appl., 46 (2003), 279-291.

[7] J. W. Luo, L. DeBnath, Oscillations of second order nonlinear ordinary differential equations with impulses, J. Math. Anal. Appl., 240 (1999), 105-114.

[8] Z. G. LUO, J. H. SHEN, Oscillation of second order linear differential equations with impulses, Appl. Math. Letters, 20 (2007), 75-81.

[9] A. ÖZBEKLER, A. ZAFER, Sturmian comparison theory for linear and half-linear impulsive differential equations, Nonlinear Anal., 63 (2005), 289-297.

[10] A. ÖZBEKLER, A. ZAFER, Picone's formula for linear non-self adjoint impulsive differential equations, J. Math. Anal. Appl., 319 (2006), 410-423.

[11] M. S. PEnG, W. G. GE, Oscillation criteria for second-order nonlinear differential equations with impulses, Comput. Math. Appl., 39 (2000), 217-225.

[12] J. YAN, Oscillation properties of a second order impulsive delay differential equations, Comput. Math. Appl., 47 (2004), 253-258. 